\title{
Maternal and Child Health Services
}

\author{
—Challenges and Aims-
}

By LeONa baumgartaner, M.D., Ph.D.

$\mathrm{M}^{\mathrm{s}}$ ATERNAL and child health activities, which had their beginnings far, far back in human history, have grown through the years with the technological advances and the changing social attitudes of the times. It is no more possible to predict exactly what direction they will take in the future than it would have been 25 years ago to outline today's program. Nor is the making of specific predictions a wise procedure, for public health programs must be flexible to allow for the inevitable social and technological changes. However, it is possible and it is wise to chart some sort of course for the future. An examination of the existing situation in maternal and child health-the achievements that have been made and the problems still to be solved-provides a basis for suggestions for future action.

\section{Maternal and Infant Mortality}

The greatest and most obvious achievement has been the saving of lives of infants and moth-

Dr. Baumgartner has been associated with the New York City Department of Health since 1937 and now as assistant commissioner directs its maternal, child, and school health services. In 1945 she was adviser to the French Ministry of Health, and in 1949-50 she served as associate chief of the Children's Bureau, Federal Security Agency. She is a member of the faculty of the Cornell University Medical College and of the Harvard School of Public Health.

This paper is based on material presented at the 48th annual New York State Health Conference at Lake Placid, June 1952. ers. Since 1915, the infant death rate among registered births in the United States has decreased 67 percent for the first year after birth, 80 percent for the second through the twelfth month, 52 percent for the first month, and 31 percent for the first day.

Fetal deaths too seem to have decreased. At least, the number of fetal deaths after 28 weeks of gestation now equals the number of neonatal deaths. Progress has also been made in saving the prematurely born, among whom the death rate has declined about 33 percent since 1915 . Maternal death rates have dropped phenomenally, 85 percent since that date.

Despite these successes, fetal, neonatal, and maternal deaths year after year constitute the third or fourth largest group of deaths among the total population. Much more needs to be known about how to prevent these deaths, and much more needs to be done to put into practice what is already known. It is discouraging to see, for example, that although fewer mothers die as a result of childbearing, they still die largely of preventable causes-hemorrhage, infection, toxemia.

The infant death problems are now primarily centered around deaths at or near birth. The strong probability that certain groups in the population give rise to a large proportion of the fetal and neonatal deaths indicates these groups as one place in which activities should be concentrated. The medical factors leading to pregnancy wastage obviously need further elucidation, but it should not be forgotten that the social and economic factors also may be important.

I specific area in which additional knowl- 
edge is needed is deaths of premature infants, which constitute about two-thirds of all infant deaths. Although intensive study in the past two decades has developed methods of saving the lives of these infants and large programs for their care have been inaugurated, the lack of information on how to prevent premature labor has so far precluded the establishment of a truly preventive program.

\section{Child Health and Rehabilitation}

A second noteworthy achievement is the improved health of children after infancy. The communicable diseases are largely under control, with enormous reductions in the mortality, morbidity, and crippling they once caused. In fact, so successful have been the efforts in this direction that accidents now kill more children from 1 through 15 years of age than disease.

Much still remains to be done, however. Little knowledge exists, for example, as to where or how to begin to solve the accident problem. And conditions which formerly received little or no attention-such as epilepsy, congenital heart disorder, cerebral palsy-can now be attacked.

Rehabilitation of children with handicaps or chronic diseases presents many problems. The public must be willing to support the community-wide activities of case finding, diagnosis, and therapy that are essential if maximum rehabilitation is to be secured for all. These ac- tivities are usually complicated, demanding the cooperation of more than one professional group. Few communities have so organized their resources as to make them easily available on an inclusive basis. Very real experimentation must be undertaken if all children are to have the services they need for full utilization of their assets.

Further, rehabilitation activities are not always undertaken in accord with the expectation of greatest results. Public demand seems largely to have decided what was to be done. For example, few communities have attempted to establish rehabilitation of the epileptic child, even though it appears possible to improve the condition of over 80 percent of epileptic persons at relatively little cost.

\section{Promotion of Health}

A third achievement is the enormous body of specific knowledge about the physical, mental, and emotional growth and development of children obtained through research during the past four or five decades. Research has provided many apparently unrelated facts indicating. how children differ from adults and from each other. Physical growth seems to proceed in a more or less orderly fashion according to a general pattern, but within this pattern each individual proceeds at his own pace and in his own way. A pattern is evident, too, in emotional and behavior development. Permeat-

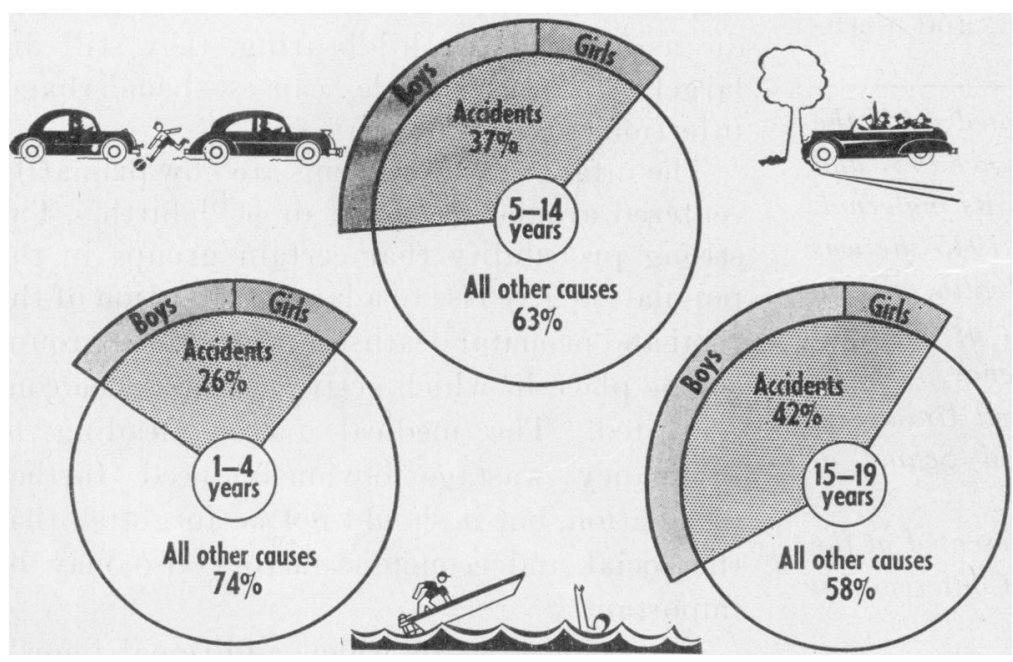

Accidents

are the greatest hazard in the lives of children. In 1948-the year on which the chart data are based-16,000 persons under 19 were killed by accidents. And the number of deaths tell only part of the story. Many more thousands of children were handicapped by accidental injury. 


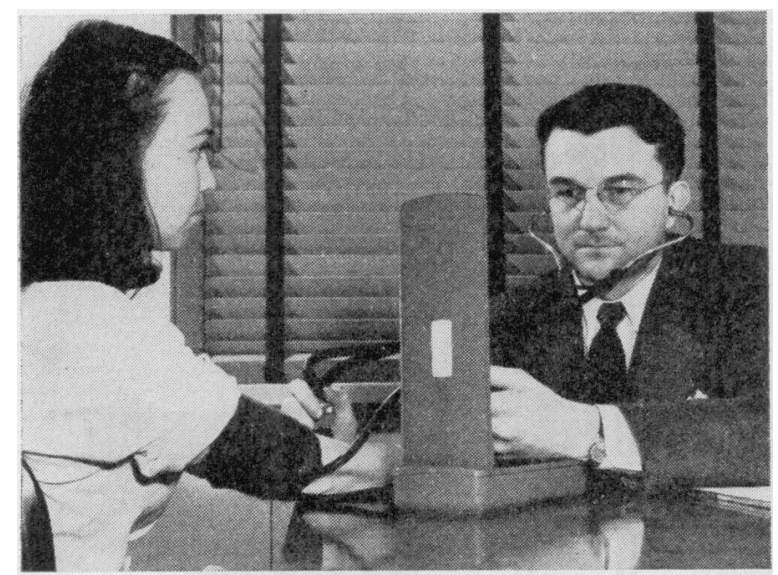

Good medical and nursing care throughout pregnancy-with supportive instructional and educational programs for parents before and after delivery - and the provision of good hospital facilities means the saving of thousands of babies and mothers. Achievements in reducing maternal deaths have been impressive,

ing the conclusions drawn from studies of all types is the concept of "readiness," that is, that the most successful attempts to train a child, to modify his behavior, are those which are timed to coincide with an appropriate stage of his development.

Particularly important for the public health expert are the clues as to the kinds of experience and environment which promote or retard optimal growth of the individual. These clues can be considered as hints for carefully planned epidemiological studies. The control of typhoid fever, for example, came after the lead provided by the Broad Street pump incident almost 100 years ag.o. Surely the environment can and should be controlled to promote the health of the child in other ways, and the process may well lead to results as spectacular as those achieved through improved environmental sanitation.

\section{Social and Economic Factors}

Certain economic and social factors which affect families and children should also be considered. Although these factors are not usually given attention by the medical and public health professions, they are certainly not re-

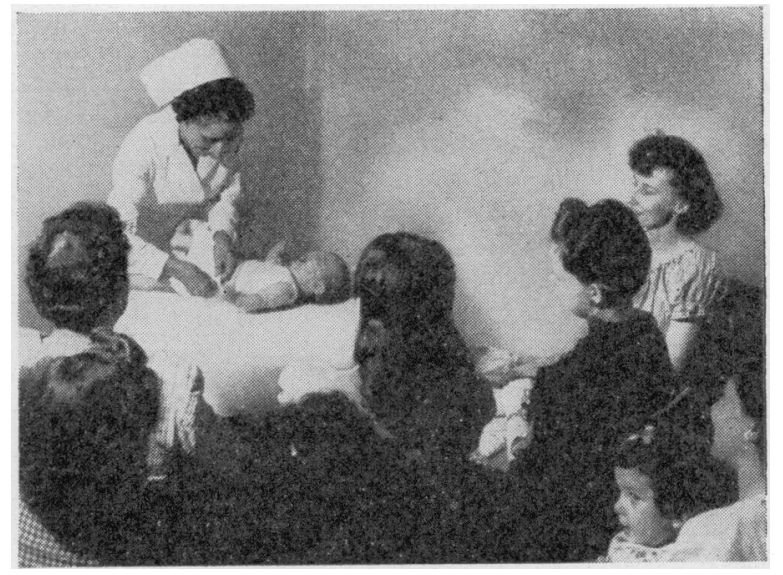

reflected in all three major causes-infection, toxemia, hemorrhage-a result largely of prenatal care plus hospital deliveries. Yet even now 1 out of 3 Negro babies is born with no medical attendance, and the needs today are greatest among Negro mothers and mothers living in rural areas.

mote from the problems confronting these professions and others interested in making the most of what medicine and public health have to offer. Five important factors deserve discussion. Figures given are derived almost entirely from the 1950 census.

Population Growth. The population is actually growing younger faster than it is growing older. In the last decade, the number of children under 5 years increased 55 percent while persons over 65 years increased only 37 percent. During the next two decades, the number of school-age children and adolescents will increase substantially. This increase in the number of children will necessitate additional child health activities just to provide the same services available today.

Younger l'arents. Couples are becoming parents at a younger age today than they did in past generations. One-third of the females in 1950 were under 20 years of age at marriage, and the median age of marriage has declined ever since 1890. Parents are, however, better educated, with some 4 years more schooling than the generations born in 1890 . Therefore, though they do not come to child-bearing with many of the specific skills and knowledges formerly acquired in the large families of yes- 


\section{Family Size and Income}

In 1949,15 percent of the Nation's 39 million families had 3 or more related children under 18 years-a total of some 23 million, or about half of all children under 18 . More than

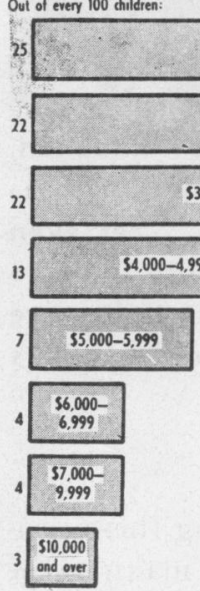

Are in tomilies with incomes (1948):

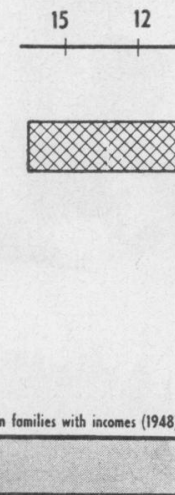

$32.000-2.999$

$3,000-3,999$
Under $\$ 2,000$
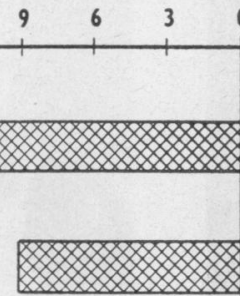
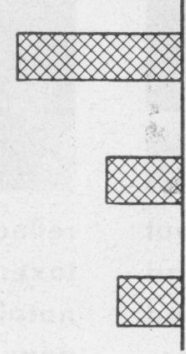

Fomilies with
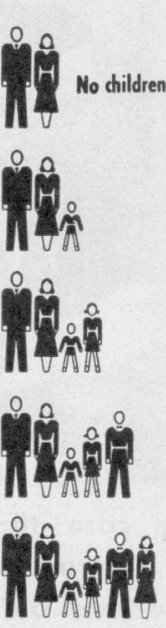

Millions of Children

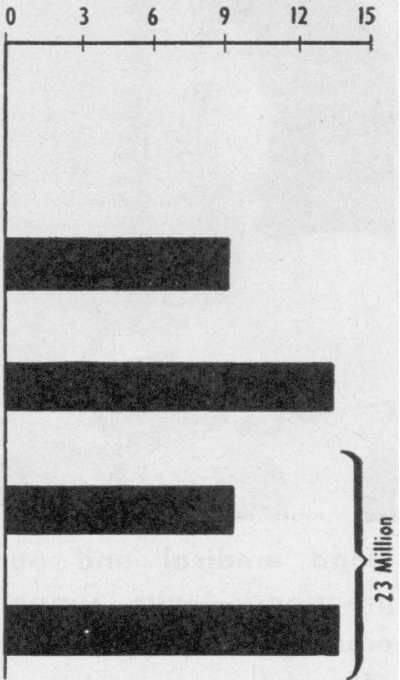

half of the families with 3 or more children and almost two-thirds of those with 5 or more live on farms or in rural-nonfarm areas. Over two-fifths of the total number of families had no children under 18, some because their children had grown up, some because of recent marriage. About 30 percent of families with related children have 2 children, and about 40 percent have only 1 child under 18 years. The chart at left indicates that most children are in low and moderate income families. Also, most large families have lower incomes than small families.

terday, parents probably can be counted on to do more themselves for their children if shown how.

Economic status. One-half of the children live in families with three or more children, and about one-half live in families with an income of less than $\$ 60$ a week. In general, the larger the family, the smaller the income. Children are concentrated, too, in relatively few families, with 16 percent of all families caring for 61 percent of all children. Because married couples become parents at a younger age than formerly, they earn less in the years when their children are young. These facts lead to the conclusion that most of our future citizens are being brought up in families in which it usually is not possible for the family alone to provide all of the health services advised.

Family Stability. In recent years great stress has been placed on how much the health and stability of the adult depend upon the support of a stable, secure family during his early years. Bowlby (1) has recently reviewed evidence showing the positive relationship between early maternal care and later mental health. These figures then may be significant: One out of $\delta$ children in the United States lives in a home that does not have 2 parents or does not live in a family at all; 1 out of 5 mothers works away from home; children born out of wedlock have increased 50 percent within the last decade, with a total of 135,000 such births occurring in 1949 , 30,000 of these to girls under 17 years of age.

Chances for Survival. The chances for survival and the quantity and quality of medical and dental care received by children vary widely in different parts of the country and in different economic groups. The recent American Academy of Pediatrics study (2) indicates that the child's very chances for survival depend upon where he lives and who his parents are. It shows, too, that doctors, even from good medical schools, have too little opportunity to learn modern pediatrics and that there are definite needs for better distribution of health and medical services and for more and better 
professional education at undergraduate and graduate levels.

These are some of the problems of maternal and child health in the United States today. Great progress has been made and significant leads have been obtained as to where to go in the future, but because of the lack of scientific knowledge in certain areas and the uncertainty as to how best to proceed in others, a great deal of uncharted sea lies ahead.

\section{Suggestions for Action}

Although the public health program for the future cannot, of course, be laid down in specific terms, the following general suggestions warrant consideration.

\section{Research}

A greatly augmented program of research into the problems of human reproduction and the growth and development-physical, mental, and emotional-of children is needed. Such a program requires the development of one or more institutes directed to the study of human beings. In institute of this type should have on its staff research persons from many fields: anatomy, obstetrics, genetics, pediatrics, statistics, embryology, physiology, chemistry, physics, and the social sciences. Among the problems lending themselves to immediate attack are

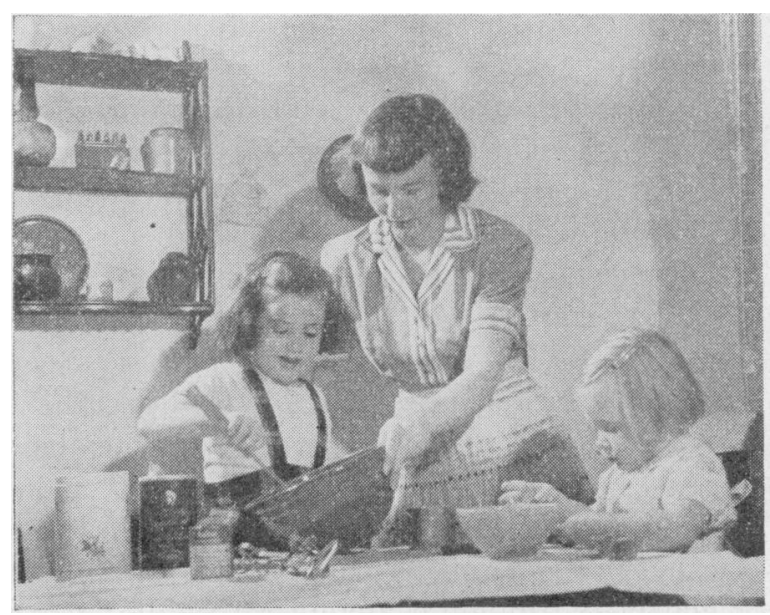

Homemaker services provided in many communities-sometimes under health department auspices-represent an important contribution to family health and child security at times when the mother is ill or temporarily disabled.

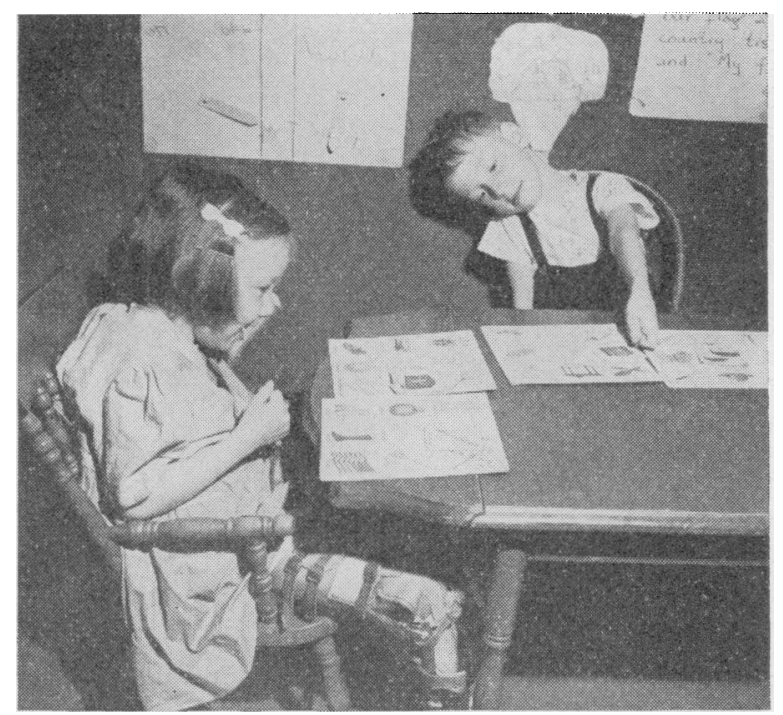

Successful attacks against many of the "common" childhood diseases have cleared the way for more aggressive approaches to some of the more stubborn problems-cerebral palsy, epilepsy, rheumatic fever, congenital heart defects, poliomyelitis.

the causes of death and malformation at or near birth and the accident problem. The apparent increase of mental illness and maladjustment also indicates further study is needed to verify or disprove the leads which the mental health movement is developing concerning personality growth.

\section{Evaluation}

A second point of attack is the development of more critical evaluation studies of ongoing services. Some of the maternal and child health programs are a half century old. Are they still meeting a public health need? If not, they should be terminated. If so, methods used and results obtained should be studied to determine if these programs are as effective as they could be.

Take, for example, school health services. The one study of the past few years that probably has had the greatest influence in this field is the so-called Astoria study (3). It attempted essentially to answer one simple question: "How can the time now spent by teacher, doctor, and nurse in the school be spent more productively?" This question needed answering and the result undoubtedly has increased the efficiency of many school health services. But in 


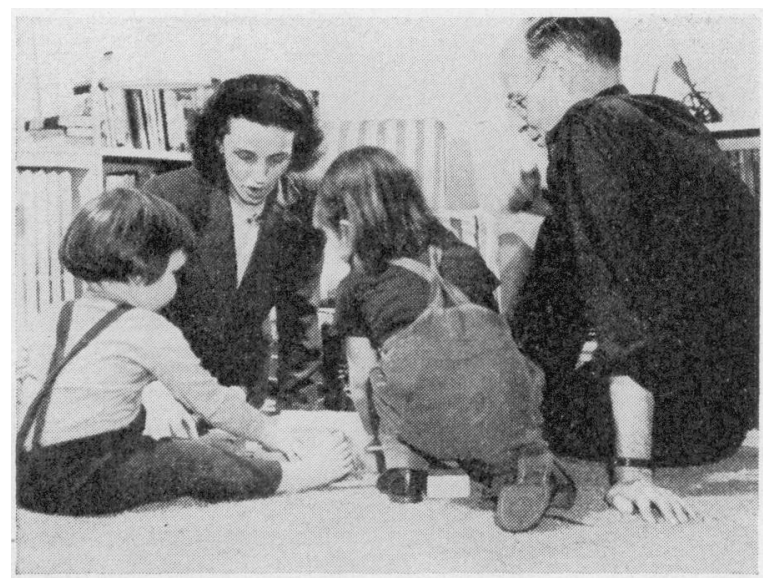

Nowhere in the country are there enough foster homes, residential treatment centers for emotionally disturbed children, or other facilities for specialized types of care. The lack is most acute outside metropolitan areas.

the light of the enormous sums spent in school health activities and the changes in the nature of the health problems of today's children, other questions need answering. Is any of the school health service time worth spending? Are there other more effective ways of locating children in need of medical care? And what are the really effective ways of securing care for those who need it? In short, what are the real health needs of today's school children?

To evaluate ongoing services will not be easy. Methods are often still to be developed. There is little tradition for such research, and few investigators are trained for or interested in this approach.

\section{Service Coordination}

A third approach is the coordination of current activities for the promotion of the child's health when he is well with those for his care when he is sick or chronically ill. Certainly, the practice of caring for the child in one clinic when he is well and in another when he is sick is not justified administratively nor is it satisfying to the family. All children need sound advice about health care and growth and development as well as specialized care for their particular ailments.

Many of the current child health problems seem to require a team approach-for example, the rehabilitation of the child with cerebral palsy, a severe hearing loss, or rheumatic fever. Isn't there some way of promoting a closer working relationship between public health personnel and the general practitioner, without whom many of the past achievements could not have been made? Wouldn't it be possible to work out an agreement whereby the general practitioner's patients could be helped by the public health nurse, nutritionist, and similar persons? Certainly, experiments can be made to determine the feasibility of providing, in one geographic location and with as far as practical the same staff, all the health services a particular child needs.

\section{Social Science Approaches}

The fourth approach should be an attempt to use more effectively some of the findings of social scientists. They stress, for example, the use of community groups having a common interest in the solving of problems which demand changes in behavior. The therapeutic value of groups such as Alcoholics Anonymous or parents of children with cerebral palsy or diabetes has been demonstrated. Why shouldn't the value of work with groups of parents of 6-month-old or 2-year-old children be tested? Attempts in this direction have been made and seem to confirm the opinion that this type of group approach has great potentialities.

Failure to focus on the whole family in a human kind of way has characterized many of our efforts in the past. The effective care of the child is a complicated process involving, particularly in early years, all the family and more than good physical care. For example, maternity care has often been interpreted as the maintenance of a complicated piece of machinery located in the female pelvis. Certainly this approach has saved thousands of lives. But hasn't something needlessly been lost in the meantime? The birth of a child is a natural function and involves all the members of the family. The recent swing to a more human approach to the expectant mother and the newborn infant in this country should be a matter of rejoicing among all public health workers. A better foundation for family life is thus being built, with no loss in effectiveness of lifesaving measures. Years ago that remarkable experiment at the Peckham Health 


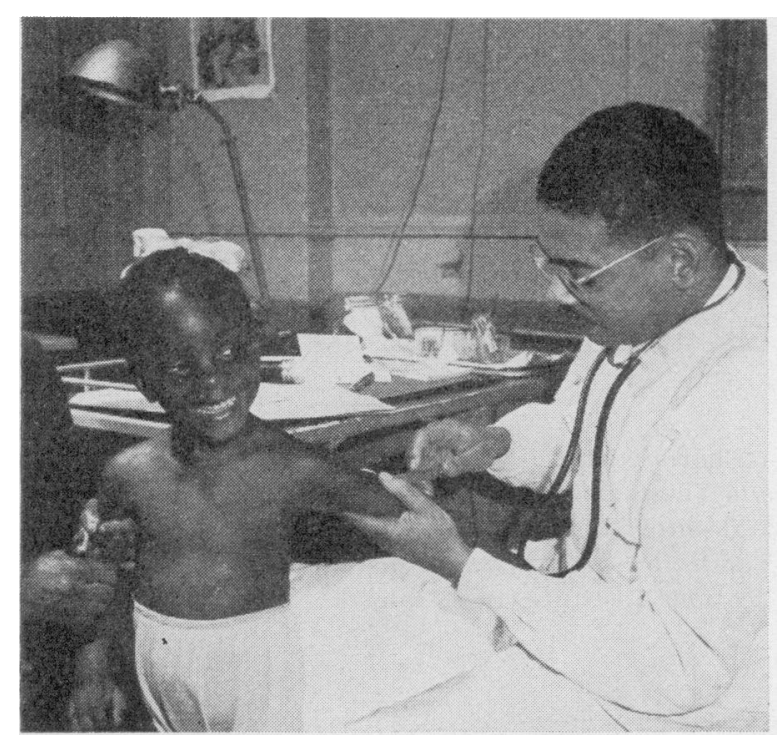

Well child care provides an opportunity to promote the emotional as well as the physical health of children. But too few children get health supervision when they are not sick. Children living in the South and in isolated counties get far less care from physicians in private practice than children elsewhere. Children living in metropolitan counties receive one-third of their care from pediatricians and other specialists, but children in isolated counties get very little service of this kind. Less than one-tenth of the well child care is given at clinics, and most clinics are held in metropolitan counties.

Center demonstrated the value of bringing the whole family in on health problems of the individual in the family (4).

\section{Possibilities for Progress}

Finally, new ways of bringing to more people the benefits of medicine and public health need to be developed. Part of the picture, as previously pointed out, involves economic problems, but there are other problems too, some relatively simple and solvable today.

For example, why is there such a wide variation in the maternal and neonatal mortality rates and in quantity and quality of maternal and infant care in the same area? Recent studies in one large urban area where well-trained physicians and nurses are found in all hospitals show startling differences in practices $(5,6)$. With hemorrhage a leading cause of maternal death, is it really interference with the practice of medicine to insist, for example, that all hos- pitals have blood readily available in the delivery room? Is it too much to require that anesthesia in the delivery room or gavage feeding in the premature nursery be given by persons who have been especially taught the techniques? Hospitals were long ago compelled to eliminate cross connections in plumbing and to drop silver nitrate in the eyes of newborn babies.

Why, despite all the evidence indicating the value of maternal care in early infancy and its relation to mental health in later life, isn't something more concrete done to provide continuity of maternal care for infants? Gains in emotional stability may be made by keeping children in their own homes instead of placing them in institutions. Much greater efforts should be made in this direction. Consider, for example, the commonly accepted practice of private and public agencies of paying more per day for the care of a child in an institution than in a foster boarding home, or the reluctance of these agencies to pay for homemakers or housekeepers to enable parents to keep children in their own homes. Is it practical not to tackle more effectively also the problem of care for the 135,000 children born annually to unwed mothers?

\section{Individual Action}

These are but a few examples of approaches to existing problems. Many of the problems await concerted action over a long period of time, and many require action which the individual health worker cannot initiate by himself. But each worker, as he performs his day-to-day tasks, can initiate action directed toward the goals suggested above.

He can, for example, reexamine his current activities to see if he is directing his major efforts toward those which apparently add to the physical, mental, and social well-being of those he serves. He can attempt to look at his daily job from a "new approach," exploring the possibilities of trying out a better way of doing the job or learning what persons of allied professions have to offer. He can add the human touch to his relations with those he serves. He can remain flexible, for the future of child health and public health lies in the ability of its 
persommel to remain flexible and creative so that they can adapt new knowledge to old problems.

\section{REFERENCES}

(1) Bowlby, John: Maternal care and mental health. World Health Organization Monograph Series, No. 2. Geneva, World Health Organization, 1951, $179 \mathrm{pp}$.

(2) American Academy of Pediatrics: Child health services and pediatric education. New York, Commonwealth Fund, 1949, $270 \mathrm{pp}$.

(3) Nyswander, Dorothy B.: Solving school health problems. New York, Commonwealth Fund, 1942, $377 \mathrm{pp}$.

(4) Pearse, Innes H., and Crocker, Lucy H.: 'The Peckham experiment. A study of the living structure of society. London, George Allen and Unwin, Ltd., 1943, 333 pp.

(j) Wallace, H. M., Gold, F. M., Losty, M. A., Rich, $H$. : Criteria for the evaluation of the quality of maternity and new-born care. Am. J. Pub. Health 42: 499-507 (1952).

(6) New York Academy of Medicine, Committee on Public Health Relations: Infant and maternal care in New York City. New York, Columbia University Press, 1952, 188 pp.

Charts with this paper are adapted from: Children and Youth at Midcentury-a chart book, issued by the Midcentury White House Conference on Children and Youth and published and distributed by Health Publications Institute, Inc., Raleigh, N. C.

\section{Children's Bureau Reports 1951 Adoptions}

Nearly half the children adopted in 1951 by persons not related to them were placed in adoptive homes without the safeguards that both the children and parents should have, according to the Children's Bureau, U. S. Department of Health, Education, and Welfare. Fortyeight percent of children adopted by nonrelatives were placed into the adoptive home independently of a social agency.

The Children's Bureau report on adoptions in 1951 was prepared from data furnished by State public welfare agencies, on the basis of which the Bureau estimates that probably 80,000 adoption petitions were filed during the year. This is a 60 -percent increase over adoption petitions filed in 1944 .

The report attributes the increase in adoptions to the large number of homes broken by death, divorce, or desertion during and following World War II, and to the increase in the number of children born out of wedlock.

The average age of the children for whom adoption petitions were filed was 3.3 years in the 25 States reporting substantially complete information for 1951. Two-fifths of the children were under 2 years of age at the time the adoption petition was filed.

In independent placements, more than half of the children were under 1 month of age at the time of placement. This means that many of these children were placed either directly from the hospital or shortly thereafter. Only 11 percent of the children placed by agencies were under 1 month.

In the 25 States reporting complete information on adoption petitions, the number of adoptive children was almost equally divided between those born out of wedlock and those born in wedlock. Nonrelated persons filed adoption petitions for 69 percent of the adoptive children born out of wedlock but only 25 percent of those born in werllock. 